\title{
A NEW CONCEPTUAL MODEL FOR AEOLIAN TRANSPORT RATES ON BEACHES
}

\author{
Sierd de Vries ${ }^{1}$, Marcel Stive ${ }^{2}$, Leo van Rijn ${ }^{3}$ and Roshanka Ranasinghe ${ }^{4}$ \\ In this paper a new conceptual model for aeolian sediment transport rates is presented. Traditional sediment transport \\ formulations have known limitations when applied to coastal beach situations. A linear model for sediment transport \\ rates with respect to wind speed is proposed and supported by both data and numerical model simulations. The \\ presented model does not solve complex wind fields and is therefore very easily applicable. Physical principles such \\ as the presence of a threshold velocity and interaction with the bed surface are yet to be implemented before the \\ model can be used for predictive purposes.
}

Keywords: Aeolian transport; field measurements; model concept

\section{INTRODUCTION}

This paper presents a new conceptual model for aeolian transport with the aim of contributing to the predictive capabilities regarding dune development on the annual to decadal timescale.

Dune management is often based on reactive strategies where dunes are stabilized and or reinforced when certain safety criteria are not met. However, recent coastal management strategies explore the possibilities on how to use natural processes in a proactive way to build, maintain and reinforce dunes and the accompanying protective function (see for example Aarninkhof et al. (2010)). This approach is driven by the challenging possibility of integrating coastal protection and natural development to an interdisciplinary coastal management strategy, Building with Nature (Waterman, 2010).

Traditionally, aeolian sediment transport is modeled using Bagnold type formulations (Bagnold, 1954). Bagnold type formulations relate sediment transport to shear velocities to the $3^{\text {rd }}$ power. He defined the main factors influencing aeolian transport rates (q) are the grain diameter (d) relative to a reference grain diameter (D), the air density $(\rho)$, the gravity acceleration $(g)$, the shear velocity $(u *)$ and an empirical coefficient (C).

$$
q=C \frac{\rho}{g} \sqrt{\frac{d}{D}} u_{*}^{3}
$$

This approach assumes there is sufficient sediment supply to achieve transport limited conditions where a wind dependent transport capacity governs aeolian sediment transport rates. At beaches, sediment transport systems are typically supply limited (Davidson-Arnott and Law, 1990) where the aeolian transport rates are very much influenced by the supply of sediment. This sediment supply is variable in time and dependent on beach geometry, surface sediment characteristics, surface moisture content (Davidson-Arnott et al., 2005).

Previous attempts to relate predicted sediment transport rates to measured sediment transport rates in the field have (without notable exception) used Bagnold's power law principles. It turns out that with some tuning of coefficients, reasonable agreements between short scale measured and modeled sediment transport could be achieved. However, using these tuned Bagnold type equations leads to a general over prediction of total transports when integrating over longer timescales (Sherman et al., 1998) greatly reducing the predictive skills of using Bagnold type equations.

In any 1D (in the direction of the wind) aeolian sediment transport system, total transport (Qs $[\mathrm{kg} / \mathrm{s}])$ is determined by sediment concentration $(\mathrm{Cc}[\mathrm{kg} / \mathrm{m}]$ in the direction of the wind) and sediment velocity $(\mathrm{Us}[\mathrm{m} / \mathrm{s}])$.

$$
Q_{s}=C_{c} \times U_{s}
$$

Bagnold type formulations assume the sediment concentration to be dependent on wind conditions (indirectly trough conservation of momentum). In supply limited conditions this is not necessarily the case while in the extreme case of a pure supply limited system, Cc could be assumed independent of wind conditions and governed by sediment supply only. This reduces the complexity of the sediment transport relation with respect to wind towards a linear relation where total transport is a function of

\footnotetext{
${ }^{1}$ Section of Hydraulic engineering, Delft University of Technology, Sierd.deVries@tudelft.nl.

${ }^{2}$ Section of Hydraulic engineering, Delft University of Technology, M.J.F.Stive@tudelft.nl

3 Deltares Delft, Leo.vanRijn@deltares.nl.

${ }^{4}$ Delft University of Technology also at UNESCO-IHE, R.Ranasinghe@unesco-ihe.org
} 
supply times the speed of which this supply is transported. It seems reasonable to assume the sediment speed to be proportional to the wind speed. Assuming that beaches are supply limited system we hypothesize that: Aeolian sediment transport rates at beaches are linearly related to wind conditions. In the remainder of this paper the hypothesis is illustrated using measured field data and a conceptual numerical model.

\section{FIELD CAMPAIGN}

A five day field campaign at a beach along the Dutch coast is conducted to investigate the influence of wind speed and sediment supply on measured sediment transport rates. Wind speed and direction are measured together with sediment transport rates at 5 locations across the beach. For 3 days winds were normally incident (onshore) and sediment transport was continuously measured. In this paper we discuss measured transport at one location at the middle of the beach some $40 \mathrm{~m}$ downwind from the high water line. Figure 1 shows hourly averaged measured wind speeds, cumulative transports and hourly averaged tidal levels.

Figure 1 shows that, during relatively constant wind conditions, measured counts at the upper beach fluctuate with the tidal excursion. Low tide relates to relatively high transports with respect to hight tides. Cross correlations show that the tidal elevation explains a large part (46\%) of the total variance in the measured sediment transport. Moreover, it cannot be confirmed if wind related transport capacity is reached at any time during the experiment, it could be of a higher order than the measured transports.

Figure 2 shows the relation between the measured wind speeds and sediment transport rates during two arbitrary hours of the total dataset. To reduce scatter, sediment transport rates are averaged per velocity bin showing only the average sediment transport rates per bin. Fitting a linear curve trough these data provides a decent fit. The gradient of the linear fit relates to the average sediment concentration over the considered period (via Equation (2)). This steepness and therefore the average sediment concentration is shown to vary over time. This temporal variation is likely caused by the reduction of the source area due to effect of the tide. The zero crossing of the linear fit defines a threshold wind speed which seem to converge for this specific example. While fitting a cubic curve provides a slightly better fit in this case the cubic fit does not deviate substantially from the linear fit and could therefore be argued to as not significantly better.
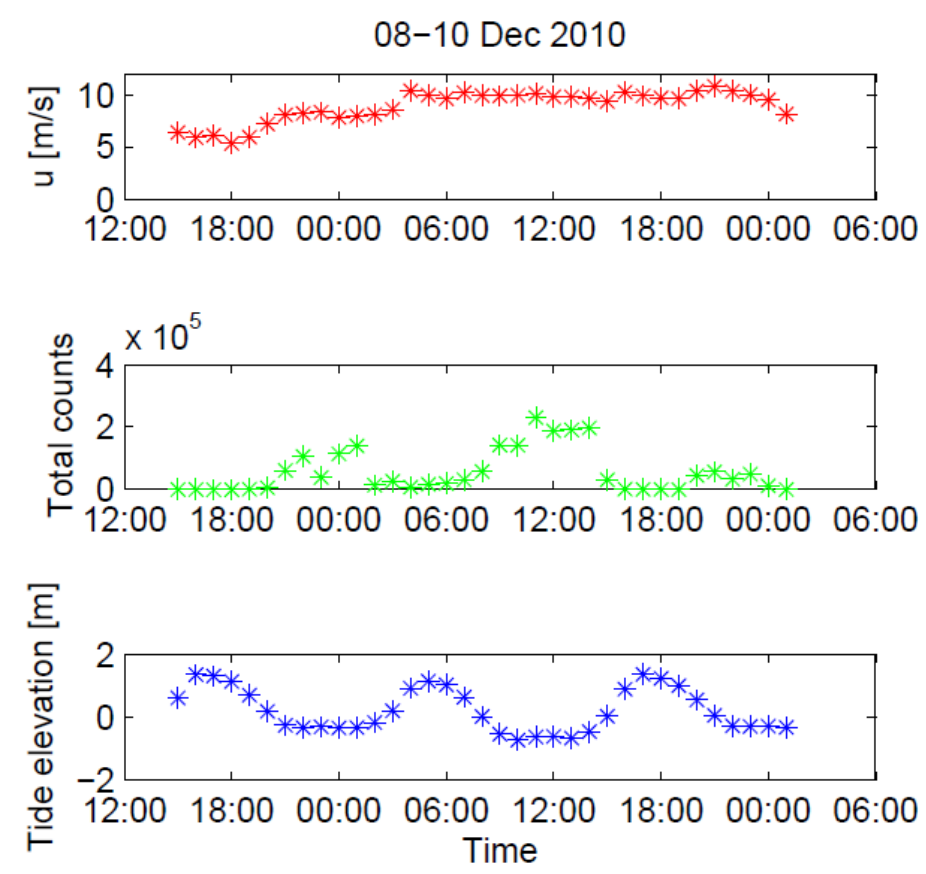

Figure 1: Top panel shows hourly averaged measured wind conditions measured on the beach. Middle panel shows cumulative measured transport [saltiphone counts] at the upper beach. Bottom panel shows hourly averaged tidal excursion. 


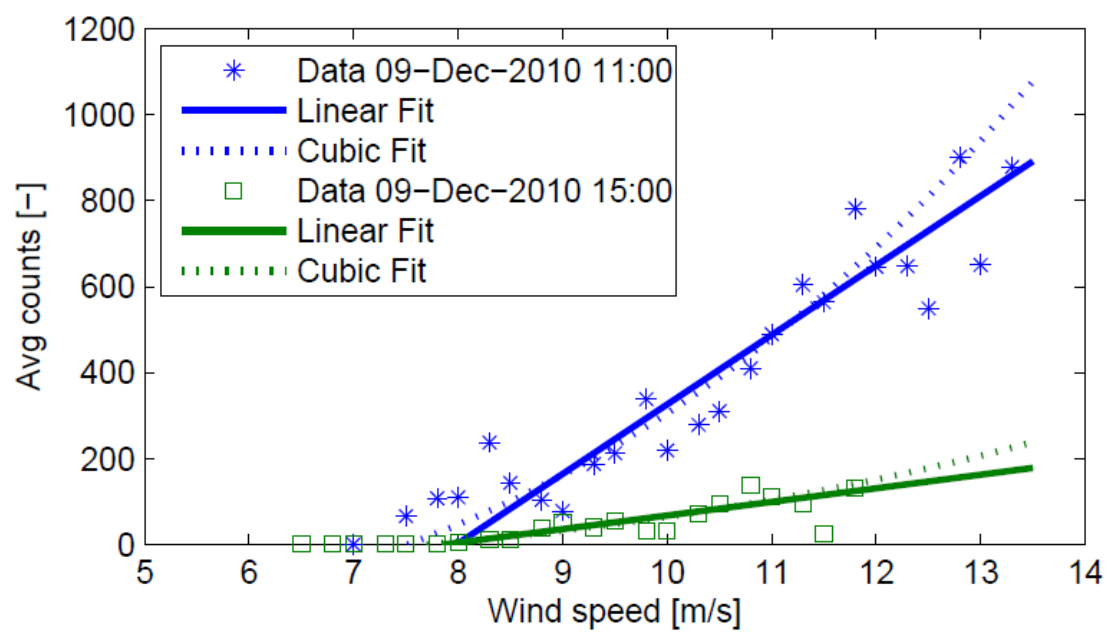

Figure 2: Relation between measured sediment transport rates and wind speed on a beach averaged over 2 arbitrary hours (out of $\mathbf{3 6}$ hours available).

\section{MODELLING A SUPPLY LIMITED SYSTEM}

In order to interpret the measurements and the fitted linear trend presented in the previous section we have set up a numerical model where the concept of a supply limited situation is implemented.

Figure 3 shows the spatial domain of the model where an explicit supply zone is present. At the west (upwind) boundary of the domain sediment transport concentration is 0 and could physically represent the waterline in beach situations during onshore winds. The sediment transport concentration in downwind direction is dependent on the source magnitude and wind velocity.

The magnitude of the supply in the supply zone (in $\left[\mathrm{Kg} \mathrm{s}^{-1} \mathrm{~m}^{-1}\right]$ ) is assumed to be limited and independent of the wind speed. It is assumed that all source material is transported towards the downwind boundary. As a result the sediment transport concentration increases in the direction of the wind in the supply zone.

Figure 4 shows the consequence of a supply limited system and a transport limited system on the spatial distribution of the sediment transport rates. The supply zone covers the spatial extent of 0-20 m. In the supply limited case the sediment transport capacity by the wind is not reached and the sediment transport rates at any location are governed by the cumulative supply in upwind direction only.

When the carrying capacity of the wind is not enough to mobilize and transport the total amount of available sand in the supply zone, a sediment transport capacity is reached inside the supply zone. While there is still sediment available in downwind direction, transport does not increase as the transport capacity of the wind is reached. When sediment transport rates equal the carrying capacity of the wind the system is transport limited rather than supply limited (Davidson-Arnott and Law, 1990).

The conceptual model can account for a supply limited system where total transport is governed by supply and a transport limited model where total transport is governed by the transport capacity by wind. In both cases a steady state spatial distribution of sediment transport rates is obtained. Focusing on the supply limited case a time dependent wind velocity is introduced. While the sediment transport rates are still governed by the source, the sediment concentration (Cc) and the sediment speed (Us) of the sediment vary where the distribution of the sediment concentration in space and time $\left(\mathrm{Cc}_{\mathrm{j}}^{\mathrm{n}}\right)$ is solved using the following discretized continuity equation.

$$
\frac{C c_{j}^{n+1}-C c_{j}^{n}}{\Delta t}+U_{s}^{n} \frac{C c_{j+1}^{n}-C c_{j}^{n}}{\Delta x}=\frac{\text { Source }_{j} / h}{T}
$$

Where $\mathrm{h}$ is the height of the transport layer and $\mathrm{T}$ an adaptation timescale. The inititial condition $\mathrm{Cc}_{\mathrm{j}}^{0}=0$ and the boundary condition $\mathrm{Cc}_{0}^{\mathrm{t}}=0$. Sediment transport rates are calculated using Equation (2). 

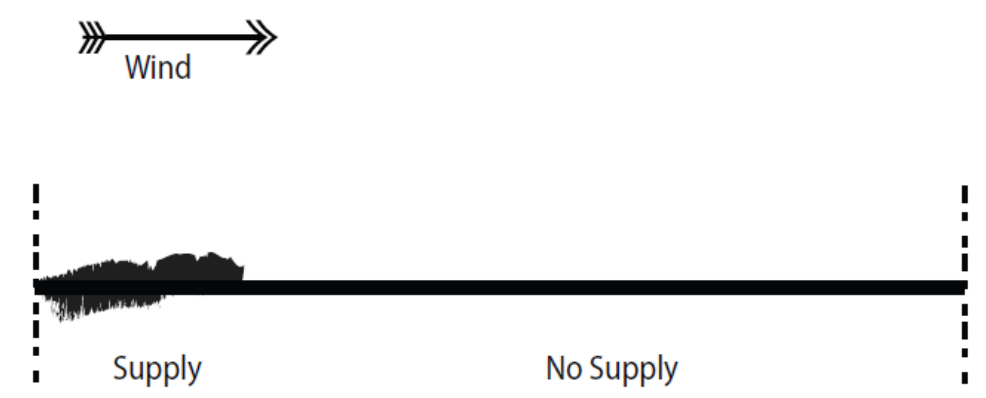

Figure 3: Simple representation of a supply limited system where wind is from left to right.

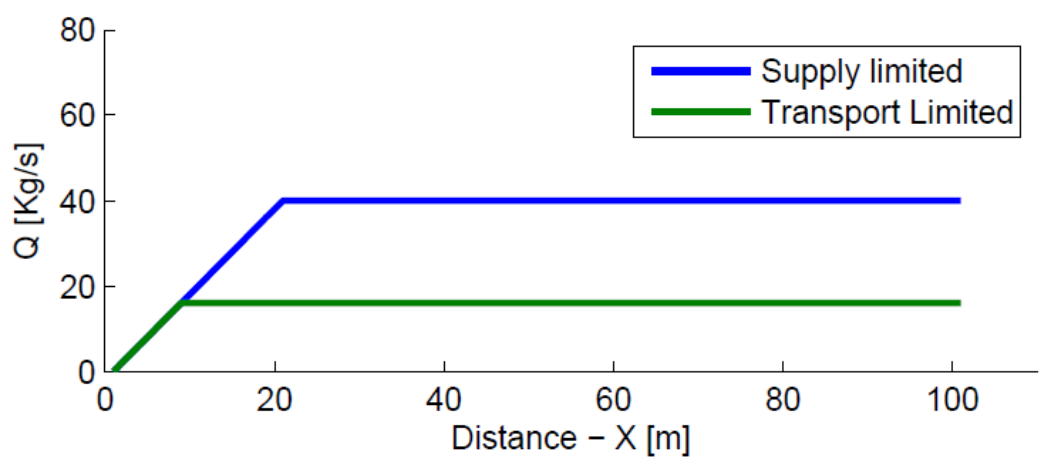

Figure 4: Spatial distribution of sediment transport rates. Lines indicate steady state situations in time (constant wind).

Temporal and spatial fluctuations in sediment concentrations exist due to wind fluctuations. Figures 5 and 6 show the adaptation of the spatial distribution of the sediment concentration where the advection velocity has changed in time. Figure 5 shows that the spatial distribution of the sediment concentration shows a transition between two steady state solutions. Figure 6 shows that when considering a location in downwind direction of the source area, fluctuations in sediment transport rates could be caused by momentary fluctuations in wind speed (see figure $6 \mathrm{t}=500 \mathrm{~s}$.) but also by the somewhat lagged effect of the changing conditions in the 'remote' source area (see Figure 6 around $\mathrm{t}=800 \mathrm{~s}$.).

When inducing fluctuating winds on a shorter timescale, steady state conditions such as shown in figures 4, 5 and 6 are unlikely to occur. Figure 7 shows the calculated temporal development of the sediment concentration and sediment transport rates at the downwind boundary as a function of a fluctuating advection speed. The fluctuating wind forcing time series is randomly generated to be between 0.5 and $1 \mathrm{~m} / \mathrm{s}$. Both sediment concentration and sediment transport rates show a mean component with some fluctuation around the mean.

Figure 8 shows the relationship between wind speed and aeolian sediment transport rates at the downwind boundary as calculated by Equation (3). A clear linear signal is present and a linear model can be fitted. The steepness of the linear line indicates the average sediment concentration which is determined by the sediment supply and the average wind conditions. To illustrate the above, an additional calculation is shown where the source magnitude in the supply zone is halved. Figure 8 depicts that when supply is halved the steepness of the linear fit is halved as well. 

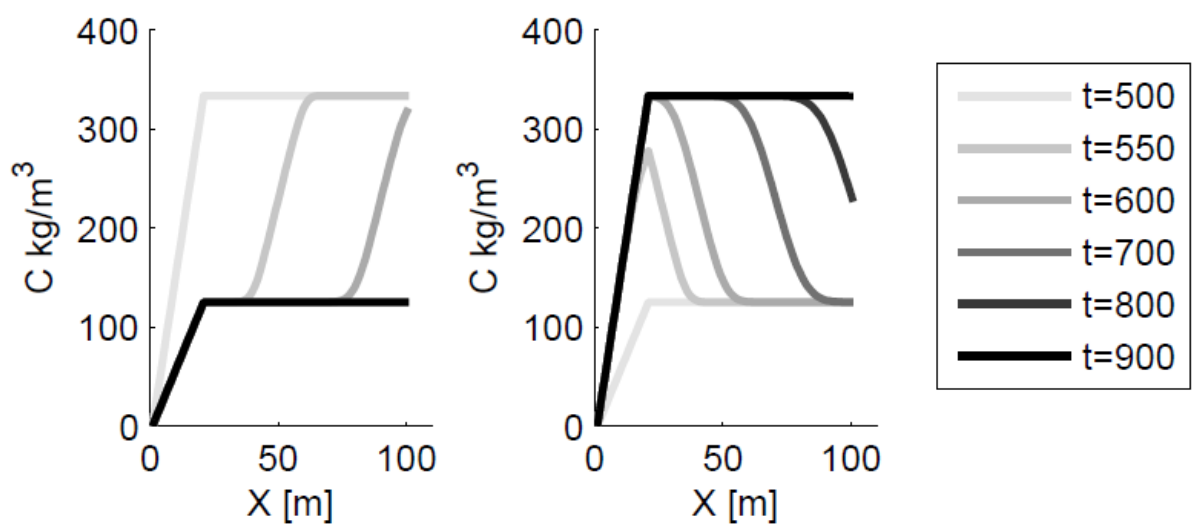

Figure 5: Spatial distributions of sediment concentration. Left panel shows an increasing wind from 0.3 to $0.8 \mathrm{~m} / \mathrm{s}$ at $\mathrm{t}=500 \mathrm{~s}$. Right panel shows a decreasing wind from 0.8 to $0.3 \mathrm{~m} / \mathrm{s}$ at $\mathrm{t}=500 \mathrm{~s}$ (see also Figure 6 ).
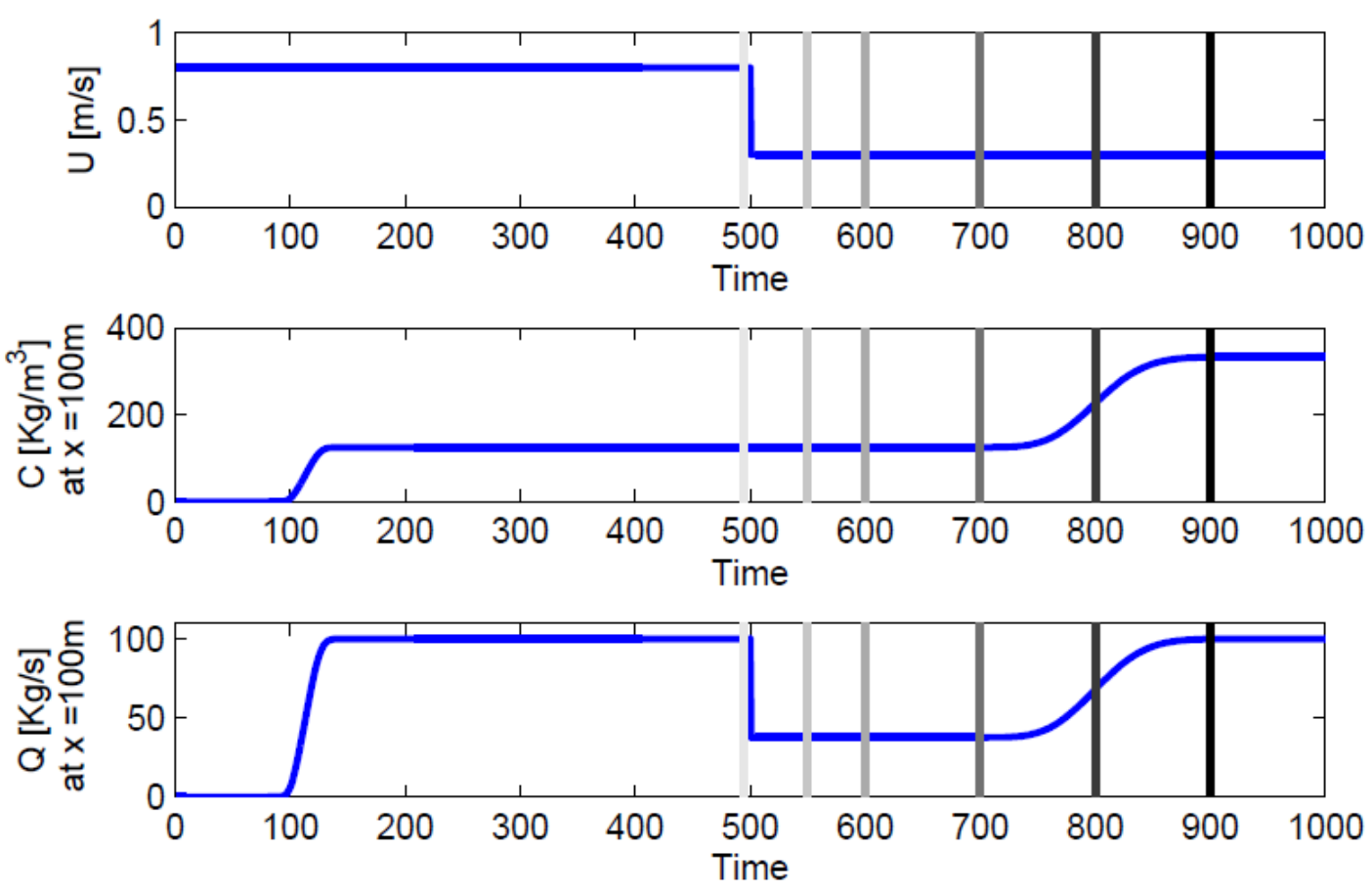

Figure 6: Top panel shows the temporal development of the advection speed for the case of increasing advection speed (right panel figure 5). Middle panel shows the temporal distribution of the sediment concentration at location Distance $=100 \mathrm{~m}$. Bottom panel shows the temporal distribution of the sediment transport rates at location Distance $=\mathbf{1 0 0} \mathrm{m}$. Vertical black lines indicate times corresponding to Figure 5 

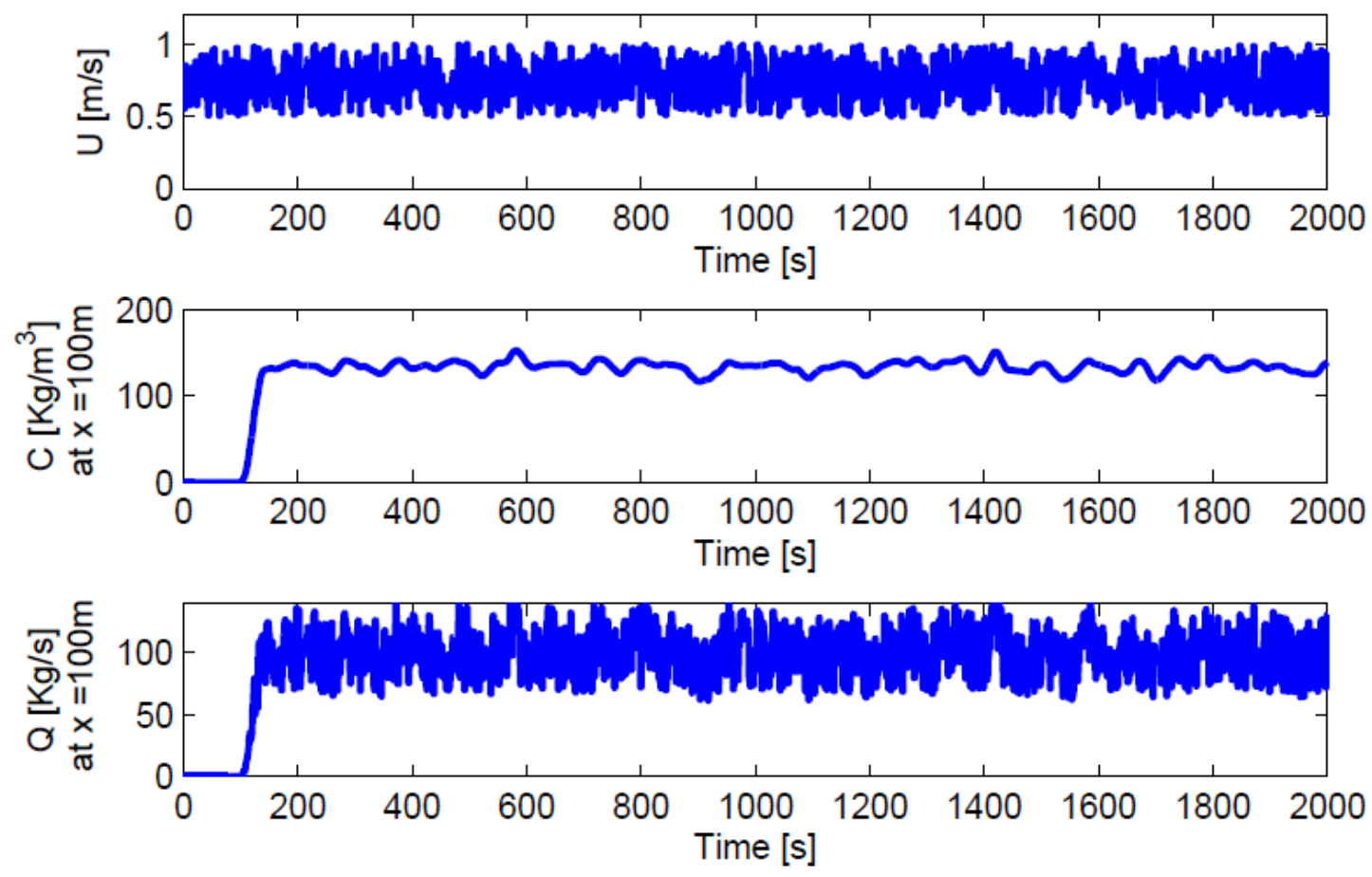

Figure 7: Top panel shows the temporal development of the advection speed showing fluctuations on the short timescale. Middle panel shows the calculated temporal distribution of the sediment concentration at location Distance $=100 \mathrm{~m}$. Bottom panel shows the calculated temporal distribution of the sediment transport rates at location Distance $=100 \mathrm{~m}$.

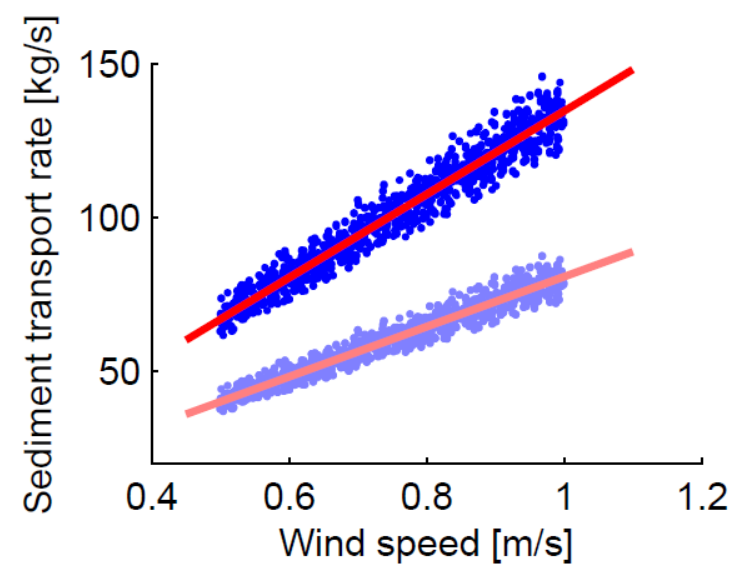

Figure 8: Sediment transport rates as a function of wind speed at downwind boundary. The dark blue dots represent data which are identical to the data presented in Figure 7 with the exception that the first 200 seconds are discarded. The dark red line represents the best linear fit. The light blue dots and light red fitted trend is obtained in a similar matter but supply is reduced with respect to the dark dots and fitted line. 


\section{DISCUSSION, CONCLUSIONS AND FUTURE WORK}

It is attempted to explain measured data of wind speed and sediment transport rates using an initial conceptual model. Possibly, the model presented above could be used as an additional tool to further interpret the current data but also previous field data. While the model is still in initial stage it already gives an indication on how sediment transport rates and concentrations develop in space and time in a supply limited situation. The model indicates that in the assumed supply limited situation the relation between sediment transport rates and wind speed could be argued to be linear where the steepness of the fitted linear trend indicates a measure of the conditions at the source area. Based on this, previously collected field data could be re-analyzed with a specific focus on the conditions in the source area where the magnitude of the source and the variability could be quantified fitting linear relationships to data such as in Figure 2. Possible field datasets to be re-analysed are amongst others the ones presented by Davidson-Arnott et al. (2005); Davidson-Arnott and Bauer (2009); Arens (1996) which are currently analyzed fitting traditional higher order Bagnold type relations.

This rather simplified principle of aeolian sediment transport stresses the importance of sediment supply to the total sediment transport rates with respect to wind conditions. It gives a new, easy to use concept for predicting aeolian transport budgets and hence dune development where sediment supply is the most important governing parameter. Moreover, as wind fluctuations are considered of lesser importance, complex and computationally challenging calculations of flow patterns are no longer needed when predicting aeolian sediment transport rates.

The present conceptual model can possibly be extended to a future predictive tool. Therefore the possibilities of including essential processes are to be explored. Adaptations which are currently foreseen to be essential and should be implemented are the inclusion of a threshold velocity for transport, a formulation for sediment pickup from the bed, sediment exchange and feedback with the bed.

\section{ACKNOWLEDGMENTS}

This work was funded by the innovation program Building with Nature. The Building with Nature program is funded fromseveral sources, including the Subsidieregeling Innovatieketen Water (SIW, Staatscourant nrs 953 and 17009) sponsored by the Dutch Ministry of Transport, Public Works and Water Management and partner contributions of the participants to the Foundation EcoShape. The program receives co-funding from the European Fund for Regional Development EFRO and the Municipality of Dordrecht.

\section{REFERENCES}

Aarninkhof, S., van Dalfsen J.A., Mulder, J., Rijks, D., May 2010. Sustainable development of nourished shorelines: Innovations in project design and realization. In: Proceedings of PIANC MMX Congress. Liverpool UK.

Arens, S. M., 1996. Rates of aeolian transport on a beach in a temperate humid climate. Geomorphology 17 (1-3), 3 - 18.

Bagnold, R. A., 1954. The physics of blown sand and desert dunes, 2nd Edition. Methuen, Lonon.

Davidson-Arnott, R. G. D., Bauer, B. O., 2009. Aeolian sediment transport on a beach: Thresholds, intermittency, and high frequency variability. Geomorphology 105 (1-2), 117-126.

Davidson-Arnott, R. G. D., Law, M. N., 1990. Seasonal patterns and controls on sediment supply to coastal foredunes, long point, lake erie. In: Nordstrom, K. F., Psuty, N. P., Carter, R. W. G. (Eds.), Coastal Dunes: Form and Process. John Wiley \& Sons Ltd., pp. 177-200.

Davidson-Arnott, R. G. D., MacQuarrie, K., Aagaard, T., 2005. The effect of wind gusts, moisture content and fetch length on sand transport on a beach. Geomorphology 68 (1-2), 115-129.

Sherman, D. J., Jackson, D.W. T., Namikas, S. L.,Wang, J., 1998.Wind-blown sand on beaches: an evaluation of models. Geomorphology 22 (2), $113-133.8$

Waterman, R., 2010. Integrated coastal policy via Building with Nature. Ph.D. thesis, Delft University of Technology. 